\title{
Bacterial lipopolysaccharide induces increased expression of toll-like receptor (TLR) 4 and downstream TLR signaling molecules in bovine mammary epithelial cells
}

\author{
Eveline M. IbEAGHA-AWEMU ${ }^{1}$, Jai-Wei LeE ${ }^{2}$, Aloysius E. IBEAGHA ${ }^{1}$, \\ Douglas D. BANNERMAN ${ }^{3}$, Max J.PAAPE ${ }^{3}$, Xin ZHAO ${ }^{1 *}$ \\ ${ }^{1}$ Department of Animal Science, McGill University, 21111 Lakeshore Road, Ste-Anne-De-Bellevue, \\ Quebec, H9X 3V9 Canada \\ ${ }^{2}$ Department of Tropical Agriculture and International Cooperation, National Pingtung University of Science \\ and Technology, Neipu, Pingtung, 912 Taiwan \\ ${ }^{3}$ Bovine Functional Genomics Laboratory, U.S. Department of Agriculture, Agricultural Research Service, \\ Beltsville, MD 20705 USA
}

(Received 20 April 2007; accepted 11 October 2007)

\begin{abstract}
Bovine mammary epithelial cells contribute to the innate immune response to intramammary infections by recognizing pathogens through specialized pattern recognition receptors. Toll-like receptor 4 (TLR4) is one such receptor that binds and is activated by lipopolysaccharide (LPS), a component of the outer envelope of Gram-negative bacteria. In this study, MAC-T cells (a bovine mammary epithelial cell line) were incubated in the presence or absence of increasing concentrations of LPS for $24 \mathrm{~h}$. Expression of TLR2 and TLR4 were analyzed at both mRNA and protein levels by quantitative real-time PCR (qPCR) and flow cytometry, respectively. The mRNA of both receptors were up-regulated by all concentrations of LPS used $(P<0.01)$. Similarly, flow cytometry with specific antibodies against TLR2 and TLR4 detected increased surface expression of these proteins. Furthermore, expression of downstream TLR4 signaling molecules was examined by qPCR following varying exposure times to $1 \mu \mathrm{g} / \mathrm{mL}$ of LPS. Results demonstrate that the required adaptor molecules and transcription factors were up-regulated in a time-dependent manner. Both the MyD88 dependent and independent pathways in TLR4 signaling were activated in MACT cells. Expression of TOLLIP increased in response to LPS as did the pro-apoptotic protease, CASP8. These results suggest that the bovine mammary epithelium possesses the necessary immune repertoires required to achieve a robust defense against $E$. coli. The current findings, coupled with previous findings that $S$. aureus ligands induce up-regulation of TLR4, may indicate a positive adaptation by mammary epithelial cells to effectively respond to different types of mastitis pathogens.
\end{abstract}

lipopolysaccharide / TLR4 and TLR2 / signal transduction / bovine mammary epithelial cells / mastitis

\section{INTRODUCTION}

Mammary epithelial cells mount defense against invading pathogens by detecting their respective danger signals or ligands and initiating appropriate immune responses. Tolllike receptors (TLRs) are expressed by the epithelia and other immune cells, such as

*Corresponding author: xin.zhao@mcgill.ca macrophages, neutrophils and dentritic cells, which are responsible for recognizing microbial products ranging from bacterial cell components to viral genomes [39]. To date, about 13 mammalian TLRs have been described (reviews by [1, 2, 39]) and more recently, 10 bovine TLRs have been mapped [31]. Although each of these TLRs recognizes specific ligands or pathogen associated molecular 
patterns, some pathogens are known to trigger more than one TLR $[28,38]$. TLR4 is one of the best characterized TLRs and is mainly activated by lipopolysaccharide (LPS), a component of Gram-negative bacteria. TLR2 recognizes other cell wall components including those found on Gram-positive bacteria (e.g. peptidoglycan, lipoteichoic acid, lipoproteins) and also LPS from Leptospira interrogans and Porphyromonas gingivalis.

Activation of TLR4 by LPS induces two signaling pathways known as the MyD88 dependent and independent pathways. Circulating LPS is detected by the lipopolysaccharide binding protein (LBP), which transfers it to the receptor complex CD14/MD-2/TLR4. Upon LPS binding TLR4 recruits, through its short intracellular toll-interleukin-1 receptor (TIR) domain, adaptor molecules and kinases, thus initiating a downstream signaling cascade that culminates in the secretion of pro-inflammatory cytokines and chemokines $[39,40]$. With the exception of TLR3, signal transduction by most TLRs requires the adapter molecule, myeloid differentiation factor 88 (MyD88) [1, 2, 39]. The MyD88 dependent pathway in TLR4 signaling requires the adaptor proteins TIRAP (TIR domaincontaining adaptor protein) and MyD88 to initiate a downstream cascade leading to nuclear translocation of nuclear factor $(\mathrm{NF})-\kappa \mathrm{B}$ and production of pro-inflammatory cyctokines [26]. On the other hand, the independent signaling pathway is controlled by the adaptors TICAM (toll-like receptor adaptor molecule) 1 or TRIF (TIR-domain-containing adaptor inducing interferon- $\beta$ ) and TICAM 2 or TRAM (TRIF-related adaptor molecule) which activates the transcription factor IRF3 (IFN regulatory factor 3 ) and the production of IFN$\beta[46,47]$. TIRAP is also involved in TLR2 signal transduction through the MyD88 dependent pathway [22, 45]. Thus while both TLR4 and TLR2 signaling activates NF- $\kappa B$ through the MyD88 dependent pathway, only TLR4 and not TLR2 activates IRF3. Excessive production of pro-inflammatory cytokines may lead to cellular injury and hence harmful to cells. Therefore, cytokine production and excessive pathogen growth must be con- trolled. TOLLIP (toll interacting protein) and CASP8 (caspase 8) are two molecules that are involved in these processes. TOLLIP serves as a negative regulator of TLR-signaling through modulating production of pro-inflammatory cytokines and the effects associated with over production [49]. Another defensive mechanism of the host against pathogen invasion is initiation of apoptosis, which is of special benefit against bacterial and viral infections because it could prevent multiplication of pathogens and spread of infection. Apoptosis can be initiated by members of the caspase family of cysteine proteases [11] and triggered by TLR ligands such as LPS, dsRNA, and lipoproteins [5, 24].

An array of studies conducted in the last decade with knockout mice and human cell lines has largely enabled our understanding of host immune responses, through the MyD88 dependent and independent pathways, to the presence of LPS [39]. However, specific events involving these pathways by immune cells of cattle, particularly the mammary epithelial cells, are less known. In addition, mRNA sequences and chromosomal location of most genes of TLR4 signaling molecules in cattle were not available until recently [10]. The role of mammary epithelial signaling of the immune system in response to LPS has been proven by several investigations in cattle [4, 7, 30, 32, 38]. Persson Waller et al. [32] observed a marked increase in milk and lymph interleukin (IL)-8 concentrations and milk somatic cell counts in mammary epithelial cells challenged with LPS. Similarly, Boudjellab et al. [7] observed that MAC-T cells produce IL (interleukin)-8 in response to Escherichia coli derived LPS. Furthermore, Goldammer et al. [17] noted a coordinated up-regulation of TLR4 and TLR2 mRNAs during intramammary infection induced by Staphylococcus aureus, a Gram-positive bacterium. However, little is known about the roles of TLR4 or TLR2 signaling adaptors in the translocation of NF$\kappa \mathrm{B}$ and IRF3 transcription factors which are crucial initiators of the expression of the necessary pro-inflammatory cytokines required by the mammary epithelial cells of cattle to fight invading pathogens. 
Gram-negative bacteria cause some of the most economically important diseases of cattle such as brucellosis, metritis, enteric colibacillosis, salmonelossis, coliform septicemia, mastitis, pneumonia, and campylobacteriosis [12] leading to heavy losses in the dairy and beef industries. Mastitis is the most prevalent disease in dairy herds and develops in response to intramammary bacterial infections. Efforts at controlling most of these diseases have focused on the improvement of vaccines, antibiotic therapy, and general management practices. Attention is also being focused at strengthening the innate immune response of the host to invading pathogens [29, 37]. A better understanding of the signaling mechanisms involved in innate immune responses to bacterial products by the bovine mammary gland is fundamental to facilitate the development of strategies aimed at controlling these infections.

Our aim, therefore, was to determine the response pattern of TLR4 signaling molecules in a bovine mammary epithelial cell line (i.e., MAC-T cells), following exposure to LPS derived from Escherichia coli and also to determine the expression profiles of the adaptor proteins involved in the activation of NF$\kappa \mathrm{B}$ and IRF3. We also examined the role of TLR2 owing to available lines of evidence that both TLR2 and TLR4 were up-regulated in the mammary gland after infection by Grampositive bacteria.

\section{MATERIALS AND METHODS}

\subsection{Reagents and antibodies}

LPS from Escherichia coli J5 (Rc mutant) and Dulbecco's Modified Eagle's Medium (DMEM)/Nutrient Mixture F-12 Ham were from Sigma-Aldrich (St Louis, Mo, USA). RPMI Medium 1640, Fetal Bovine Serum, Dulbecco's phosphate buffered saline (DPBS), trypsin, TRIzol ${ }^{\circledR}$ Plus RNA Purification System and SYBR $^{\circledR}$ GreenER ${ }^{\mathrm{TM}}$ qPCR SuperMix Universal were from Invitrogen Corporation. AntibioticAntimycotic solution-100x was from Biosource (Rockville, MD, USA). Phycoerythrin (PE)labelled anti-mouse/human TLR2 (clone T2.5) antibody was purchased from eBioscience (San Diego, CA, USA) and fluorescein isothiocyanate
(FITC)-labelled mouse anti-human TLR4 antibody (clone HTA125) was from Serotec (Raleigh, NC, USA).

\subsection{Cell line and culture conditions}

MAC-T, a transformed bovine mammary epithelial cell line developed by Huynh et al. [25] was used. Cells were grown to $95 \%$ confluence in the medium containing $1 \%$ each of antibioticantimycotic solution (100X) and fetal bovine serum, and $44 \%$ each of DMEM/nutrient mixture F-12 HAM and RPMI medium 1640 at $37^{\circ} \mathrm{C}$ in 5\% $\mathrm{CO}_{2}$ humidified incubator.

\subsection{LPS induction of MAC-T cells}

Confluent cells were treated with $0.00,0.01$, $1.00,5.00$, and $10.00 \mu \mathrm{g} / \mathrm{mL}$ LPS in replicates of 3 each to determine their response to different concentrations of LPS. Treated cells were grown for $24 \mathrm{~h}$ after which total RNA was isolated and the mRNA of TLR4 and TLR2 quantified by real-time PCR. In other studies, cells were seeded, grown to about $95 \%$ confluence and treated with $1.00 \mu \mathrm{g} / \mathrm{mL}$ LPS in replicates of 3 each. Total RNA was isolated at $0,2,6,12,24,48$, and $72 \mathrm{~h}$ following LPS exposure to determine the effect of LPS on the response pattern of molecules involved in TLR4 mediated signal transduction in mammary epithelial cells.

\subsection{RNA isolation and reverse transcription}

Total RNA was isolated from cells with the TRIzol ${ }^{\circledR}$ Plus RNA Purification System (Invitrogen) according to Invitrogen's instructions. The quality of extracted RNA was determined by agarose gel electrophoresis through staining with ethidium bromide and visualization under UV light. The OD260/OD280 ratio of samples was measured with NanoDrop ${ }^{\circledR}$ ND-1000 Spectrophotometer (NanoDrop Technologies Inc., Wilmington, DE, USA) and ranged from 2.05 to 2.29. Residual DNA was removed from extracted total RNA by treatment with DNase 1 (Invitrogen). RNA was then reversed transcribed into cDNA with SuperScript ${ }^{\circledR}$ III SuperMix for qRT-PCR (Invitrogen). The RT reaction mixture, which contained $2 \times$ RT reaction mix (includes SuperScript ${ }^{\circledR}$ III RT and RNaseOUT $\left.^{\mathrm{TM}}\right), 2 \mu \mathrm{L}$ Enzyme Mix $\left(2.5 \mu \mathrm{M}\right.$ oligo $(\mathrm{dT})_{20}$, $5 \mathrm{ng}$ random hexamers, $10 \mathrm{mM} \mathrm{MgCl}{ }_{2}$ and dNTPS), and $1 \mu \mathrm{g}$ total RNA, was incubated at $25{ }^{\circ} \mathrm{C}$ for $10 \mathrm{~min}$ and the temperature increased to $50{ }^{\circ} \mathrm{C}$ for $50 \mathrm{~min}$. The reaction was terminated at $85{ }^{\circ} \mathrm{C}$ 
Table I. Quantitative real-time PCR primers of TLR4 signaling molecules

\begin{tabular}{|c|c|c|c|}
\hline Molecule & Primer sequences (5' to 3') & Size (bp) & Reference sequence \\
\hline \multirow[t]{2}{*}{ *TLR4 } & TLR4 forward: ACTGCAGCTTCAACCGTATC & 190 & AY634630 \\
\hline & TLR4 reverse: TAAAGGCTCTGCACACATCA & & \\
\hline \multirow[t]{2}{*}{ TLR2 } & TLR2 forward: CAGTTTAACCCAGTGCCTTC & 241 & AF368419 \\
\hline & TLR2 reverse: CTCCAACGTCTTCAGTTGCT & & \\
\hline \multirow[t]{2}{*}{$\beta$-actin } & $\beta$-actin forward: CAAGGAGAAGCTCTGCTACG & 231 & BC102948 \\
\hline & $\beta$-actin reverse: GATGTCGACGTCACACTTCA & & \\
\hline \multirow[t]{2}{*}{ GAPDH } & GAPDH forward: TCAAGAAGGTGGTGAAGCAG & 173 & NM_001034034 \\
\hline & GAPDH reverse: TGTCGTACCAGG AAATGAGC & & \\
\hline \multirow[t]{2}{*}{ IRF3 } & IRF3 forward: CAGAGTCCCGACTCAGACAT & 103 & BC102119 \\
\hline & IRF3 reverse: ACCTCGAACTCCCAATCTTC & & \\
\hline \multirow[t]{2}{*}{ MyD88 } & MyD88 forward: ACTATCGGCTGAAGTTGTGC & 138 & NM_001014382 \\
\hline & MyD88 reverse: TCCTTGCTTTGCAGGTATTC & & \\
\hline \multirow[t]{2}{*}{ TOLLIP } & TOLLIP forward: GGCGTGGACTCTTTCTACCT & 186 & BT021785 \\
\hline & TOLLIP reverse: GTGTAGGACAGCACCAGGTT & & \\
\hline \multirow[t]{2}{*}{ TICAM2 } & TICAM2 forward: TGGCAGACAGCATTTACAGA & 131 & DQ319071 \\
\hline & TICAM2 reverse: ACAGAGTTCATGAGGGACGA & & \\
\hline \multirow[t]{2}{*}{ CASP8 } & CASP8 forward: CCAGATCTCTGCCTACAGGA & 158 & DQ319070 \\
\hline & CASP8 reverse: CTCTTCTCCATCTCCACGAA & & \\
\hline \multirow[t]{2}{*}{$\mathrm{NF}-\kappa \mathrm{B}$} & NF-кB forward: ATACGTCGGCCGTGTCTAT & 186 & XM_587432 \\
\hline & NF-кB reverse: GGAACTGTGATCCGTGTAGG & & \\
\hline
\end{tabular}

* TLR4: toll-like receptor 4; TLR2: toll-like receptor 2; $\beta$-actin: beta actin; GAPDH: glyceraldehyde-3-phosphate dehydrogenase; IRF3: IFN regulatory factor 3; MyD88: myeloid differentiation factor 88; TOLLIP: toll interacting protein; TICAM2: toll-like receptor adaptor molecule 2; CASP8: caspase 8; NF-кB: nuclear factor $\mathrm{\kappa B}$.

for $5 \mathrm{~min}$ and immediately chilled on ice. Two units of $E$. coli RNase $\mathrm{H}$ was added to the RT mixture and incubated at $37{ }^{\circ} \mathrm{C}$ for $20 \mathrm{~min}$. cDNA was further diluted with DEPC treated water and stored at $-70{ }^{\circ} \mathrm{C}$ until used.

\subsection{Real-time quantization of the mRNAs of TLR4 signaling molecules in MAC-T cells after LPS induction}

Messenger RNA of selected molecules including TLR4 and TLR2 (Table I) involved in the induction of cellular pro-inflammatory and apoptotic responses following LPS binding to the tripartite complex TLR4/MD-2 or LY96/CD14, as demonstrated in human and mouse studies [39], were quantified by real-time qPCR. Primers for qPCR were designed to have the same annealing temperature and in most cases span exon boundaries with Invitrogen's OligoPerfect ${ }^{\mathrm{TM}}$ software and synthesized by Invitrogen. The $S \mathrm{SBR}^{\circledR}$ GreenER ${ }^{\mathrm{TM}} \mathrm{qPCR}$ SuperMix Universal (Invitrogen) and the ABI 7500 Real-Time PCR System (Applied Biosystem, Foster City, CA, USA) were used in the qPCR analysis. The qPCR mix was in a final volume of $10 \mu \mathrm{L}$ and contained $1 \times \mathrm{SYBR}^{\circledR}$ GreenER ${ }^{\mathrm{TM}}$ qPCR SuperMix Universal, $200 \mathrm{nM}$ each primer, $50 \mathrm{nM}$ Rox dye, and $40 \%$ diluted cDNA. The thermal profile included an initial uracil DNA glycosylase (UDG) incubation for $2 \mathrm{~min}$ at $50{ }^{\circ} \mathrm{C}$ followed by UDG inactivation and DNA polymerase activation for $10 \mathrm{~min}$ at $95{ }^{\circ} \mathrm{C}$. This was followed by 40 cycles of $95{ }^{\circ} \mathrm{C}$ for $15 \mathrm{~s}, 56{ }^{\circ} \mathrm{C}$ for $35 \mathrm{~s}$ and $60{ }^{\circ} \mathrm{C}$ for $60 \mathrm{~s}$. The integrity of amplification indicated by a single melt peak for each product was verified by a dissociation curve analysis at $95{ }^{\circ} \mathrm{C}$ for $15 \mathrm{~s}, 60{ }^{\circ} \mathrm{C}$ for $1 \mathrm{~min}$ and $95^{\circ} \mathrm{C}$ for $15 \mathrm{~s}$ and further confirmed by the detection of a single (and expected) product after agarose gel analysis.

\subsection{Experimental considerations and statistical analysis}

In the qPCR run, each target was again replicated three times. The relative quantification method and the ABI 7500 System SDS Sequence Detection Software version 1.3.1 (Applied Biosystems) were used in mRNA quantification. Results were expressed as fold changes relative to the zero time point. Two endogenous genes, 


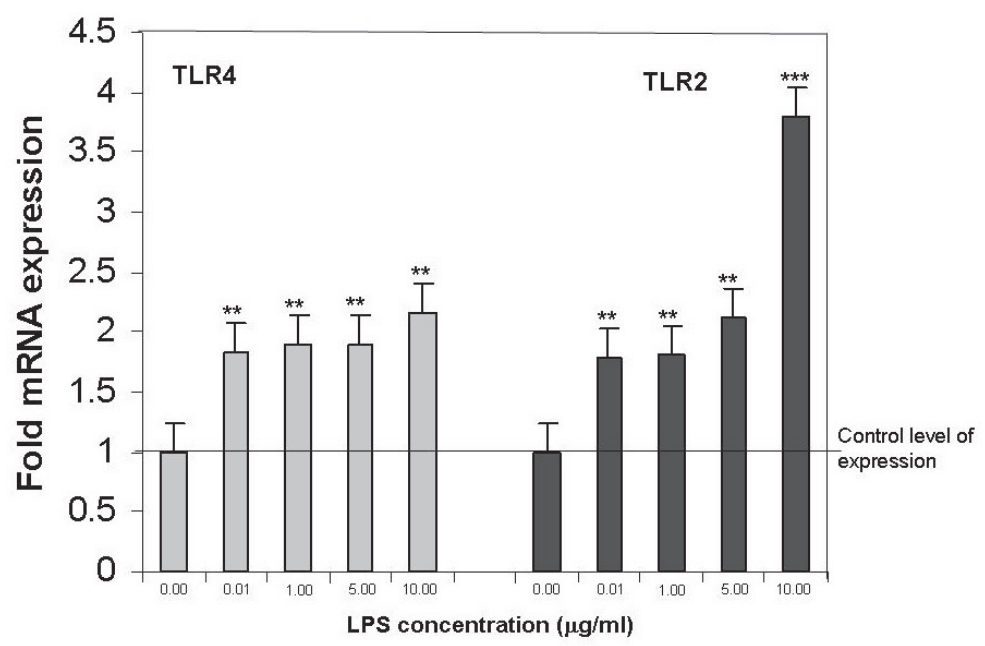

Figure 1. Relative expression ratios of TLR4 and TLR2 mRNA in MAC-T cells induced with different concentrations of LPS after $24 \mathrm{~h}$. Fold expression and significance is relative to $0.0 \mu \mathrm{g} / \mathrm{mL}$ LPS concentration. ** $P<0.01, * * * P<0.001$.

$\beta$-actin and glyceraldehyde-3-phosphate dehydrogenase (GAPDH) were initially tested for their stability in expression under the experimental conditions and found to be both stable. However, only $\beta$-actin was further used as an endogenous control. Pair-wise significance in mRNA abundance of treatments (different time points) vs. zero time point was analyzed using randomization and bootstrapping test (50 000 iterations) implemented in REST 2005 BETA version $1.9 .12^{1}$ [33]. An efficiency correction ratio for each target was used in calculating pair-wise significance.

\subsection{Flow cytometric analysis}

Based on the observed up-regulation of TLR2 by quantitative real-time PCR, flow cytometry was used to determine the surface expression of the toll proteins. Cells were grown to $95 \%$ confluence and either treated with $1.0 \mu \mathrm{g} / \mathrm{mL}$ of LPS for $24 \mathrm{~h}$ or untreated (control). Cells were washed in Dulbecco's phosphate-buffered saline (DPBS) (Invitrogen), detached by trypsin enzyme (Invitrogen) digestion and washed again. The cell suspension $\left(10^{6}\right.$ cells $\left./ \mathrm{mL}\right)$ was incubated with or without PE-labeled antimouse/human TLR2 or clone T2.5 (eBiosciences) or FITC-labeled mouse anti-human TLR4 or clone HTA125 (Serotec) antibodies for 30 to $35 \mathrm{~min}$ in the dark. Thereafter, cells were washed with $3 \mathrm{~mL}$

\footnotetext{
${ }^{1}$ http://www.gene-quantification.info/
}

of DPBS and analyzed using BD FACSAria ${ }^{\mathrm{TM}}$ (Becton Dickinson Immunocytochemistry Systems, San José, CA, USA). The TLRs were selectively gated for analysis and data were collected from 10000 events per sample. The percent fluorescence and the mean channel number of fluorescence were used as a quantitative index of TLRs response. The analysis was carried out using BD FACSDiva ${ }^{\circledR}$ software (Becton Dickinson Immunocytochemistry Systems).

\section{RESULTS}

\subsection{LPS upregulates both TLR4 and TLR2 in the bovine mammary epithelial cell line, MAC-T cells}

Stimulation of MAC-T cells with LPS upregulated significantly the mRNAs of TLR4 and TLR2 after $24 \mathrm{~h}$, as compared to non stimulated cells (Fig. 1). The expression levels of TLR4 mRNA were significantly increased (1.8-2.2 folds, $P<0.01)$ by the stimulation of all the applied concentrations of LPS when compared to the control. However, a dosedependent effect was not observed. On the other hand, the stimulation of LPS also significantly increased the expression of TLR2 mRNA. It is noteworthy that when $10 \mu \mathrm{g} / \mathrm{mL}$ of LPS was used, the fold of induction 


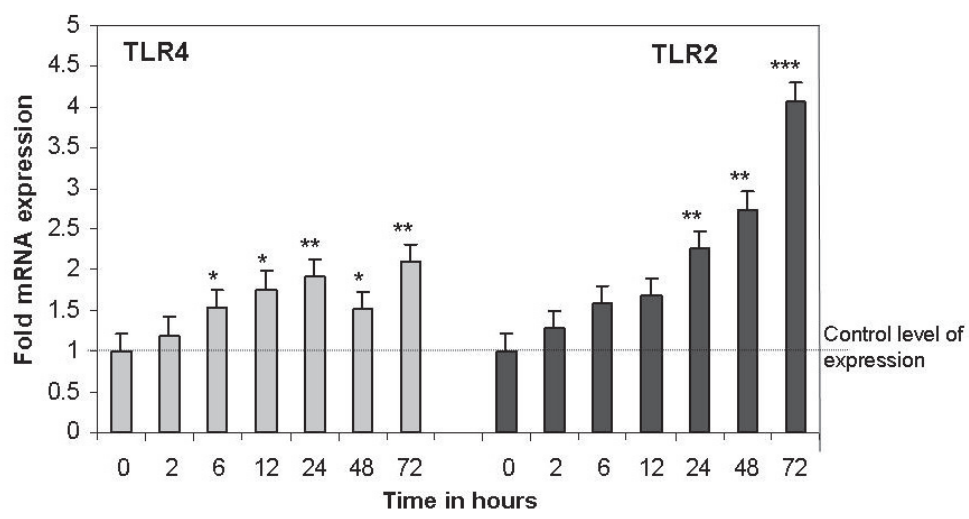

Figure 2. TLR4 and TLR2 mRNA time dependent response in MAC-T cells induced with $1.0 \mu \mathrm{g} / \mathrm{mL}$ of Escherichia coli lipopolysaccharide (LPS) or not induced (time 0 ). $* P<0.05$, $* * P<0.01$, *** $P<0.001$. Level of significance is as compared to time 0 .

increased to 3.8 , which was significantly higher than other concentrations.

A time-dependent response was studied using $1.0 \mu \mathrm{g} / \mathrm{mL}$ LPS (Fig. 2). Significant upregulation of TLR4 or TLR2 mRNA was observed as early as $6 \mathrm{~h}(P<0.05)$ or $24 \mathrm{~h}$ $(P<0.01)$ respectively, after LPS exposure. The mRNA levels of both genes increased steadily with time except for the slight decease at $48 \mathrm{~h}$ time point for TLR4.

To verify LPS-induced up-regulation of TLR2 and TLR4, specific monoclonal antibodies against these receptors were used for flow cytometric analysis of LPS-exposed mammary epithelial cells. Increased surface expression of the toll proteins was detected within $24 \mathrm{~h}$ of stimulation with $1.0 \mu \mathrm{g} / \mathrm{mL}$ LPS. The mean channel fluorescence in treated cells as compared to untreated cells was 1224 vs. 554 for TLR4 and 3394 vs. 1671 for TLR2, respectively (Fig. 3), which is similar to the results by real-time qPCR.

\subsection{Up-regulation of MyD88 and NF- $\kappa B$ in LPS stimulated MAC-T cells is time dependent}

LPS initiated the up-regulation of the adaptor molecule, MyD88 (Fig. 4). The MyD88 molecules increased gradually, as compared to untreated cells and peaked significantly $(P<0.05)$ at $72 \mathrm{~h}$ post induction. LPS-induced up-regulation of $N F-\kappa B$ occurred more rapidly than MyD88 upregulation. Within $6 \mathrm{~h}$ of exposure, the NF- $\kappa \mathrm{B}$ abundance had tripled $(P<0.01)$ and but for the slight decrease ( 0.5 fold) at the 12 th hour, increased steadily up to the 72 nd hour (Fig. 4).

3.3. The adapter molecule, TICAM 2 and the transcription factor, IRF3 of TLR4 signaling are up-regulated in response to LPS in MAC-T cells

Up-regulation of TICAM2 was mild in the first $48 \mathrm{~h}$ post induction, with a significant increase, 1.7 fold, seen at $72 \mathrm{~h}(P<0.05)$ (Fig. 5). In contrast, increased IRF3 expression was evident $12-24 \mathrm{~h}$ after LPS exposure $(P<0.05)$.

\subsection{Response patterns of CASP8 and TOLLIP in the TLR4 signaling pathway in LPS induced MAC-T cells}

TOLLIP, the negative regulator of inflammation was activated in a time dependent manner after LPS stimulation (Fig. 6). As early as $2 \mathrm{~h}$, the fold increase in the mRNA of TOLLIP had already doubled that of untreated cells (time 0 ), increased steadily with time, with the highest increase achieved at $24 \mathrm{~h}$ and decreased thereafter. These increases were significant from $2 \mathrm{~h}(P<0.05)$ post induction. LPS-induced up-regulation of CASP8 was evident from $24 \mathrm{~h}$ after exposure $(P<0.05)$ (Fig. 6). 


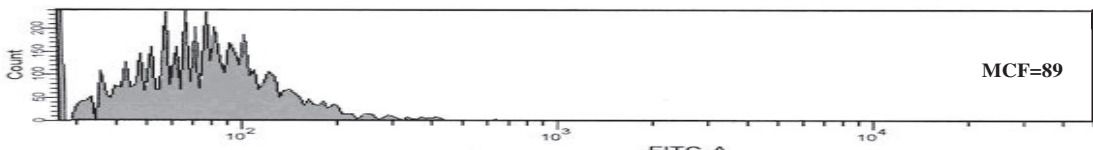

\section{TLR4}

(a)

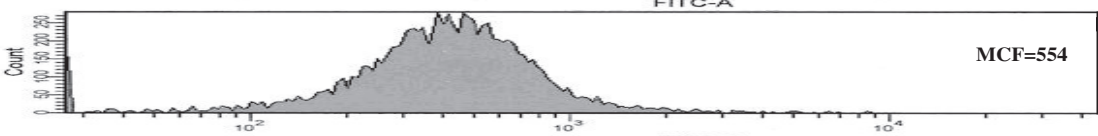

(b)

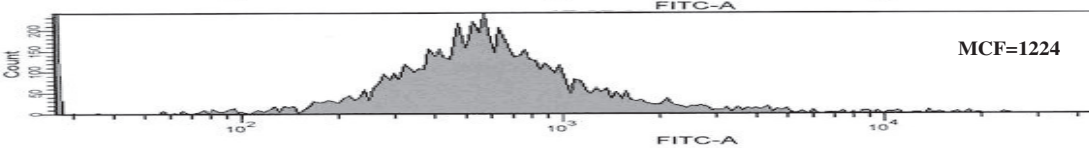

(c)

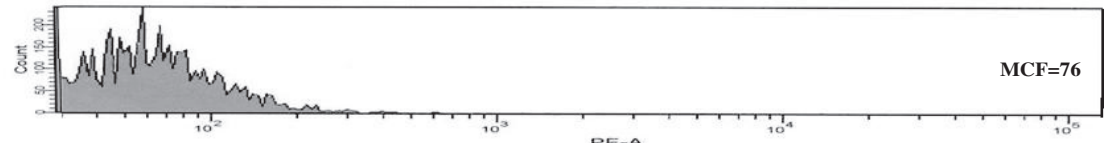

TLR2

(a)

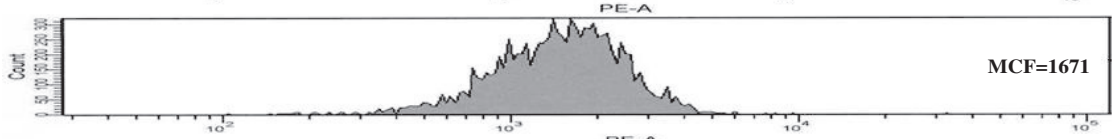

(b)

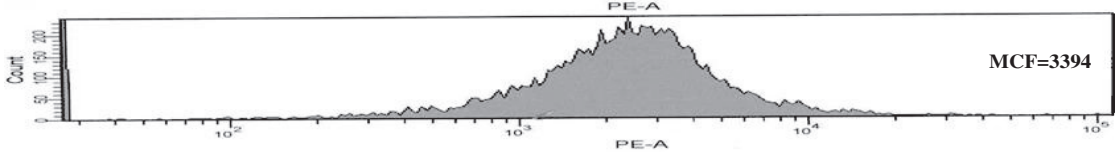

(c)

Figure 3. Histograms of flow cytometric analysis of MAC-T cells showing fluorescence intensities of unstimulated MAC-T cells (a); shift in background fluorescence intensity after unstimulated MAC-T cells have been labeled with specific antibodies for TLR4 or TLR2 (b); and MAC-T cells stimulated with $1.0 \mu \mathrm{g} / \mathrm{mL}$ LPS and labeled with specific antibodies for TLR4 or TLR2 (c). Mean channel fluorescence (mcf) of treated as compared to untreated is 1224 vs. 554 for TLR4, and 3394 vs. 1671 for TLR2.

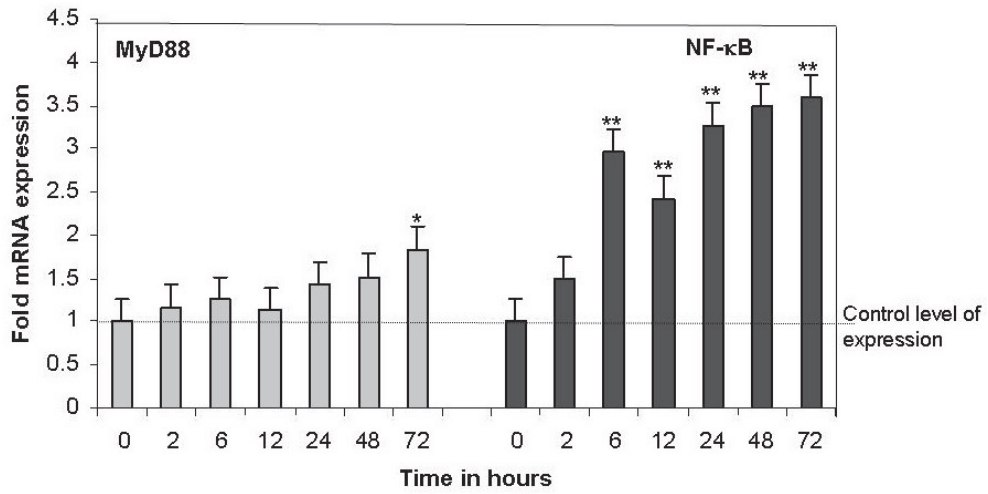

Figure 4. LPS $(1 \mu \mathrm{g} / \mathrm{mL})$ time dependent up-regulation of myeloid differentiation factor 88 (MyD88) and nuclear factor- $\mathrm{\kappa B}(\mathrm{NF}-\mathrm{\kappa B})$ in MAC-T cells. ${ }^{*} P<0.05, * * P<0.01$. Level of significance is as compared to time 0 . 


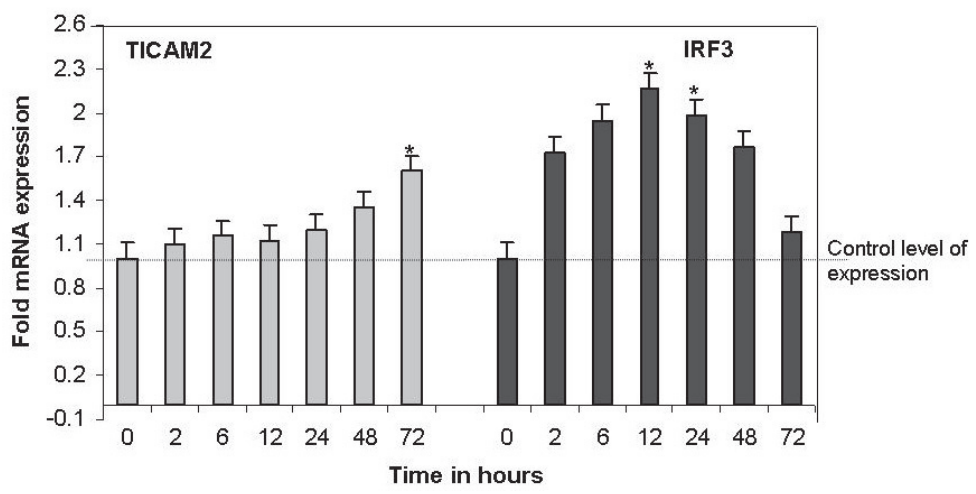

Figure 5. TICAM2 and IRF3 time dependent up-regulation in LPS $(1.0 \mu \mathrm{g} / \mathrm{mL})$ stimulated MAC-T cells. * $P<0.05$. Level of significance is as compared to time 0 .

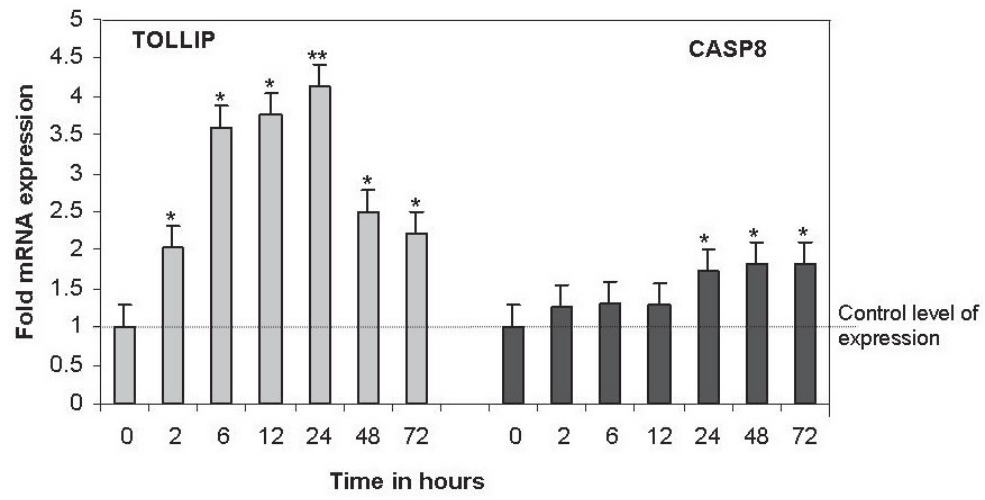

Figure 6. Response pattern of the regulatory molecules, TOLLIP and CASP8, in MAC-T cells induced by bacterial lipopolysaccharide (LPS) $(1.0 \mu \mathrm{g} / \mathrm{mL}){ }^{*} P<0.05$, $* * P<0.01$. Level of significance is as compared to time 0 .

\section{DISCUSSION}

Available lines of evidence indicate that bovine mammary epithelial cells respond to bacterial lipopolysaccharide and other microbial products by producing proinflammatory cytokines required to combat invading pathogens $[4,7,17,30,32,38]$. Other epithelial cell types (e.g. bronchial epithelial cells [18], nasopharynx epithelial cells [48], etc.) have also been shown to respond to LPS. Since Gram-negative bacteria are responsible for some of the most costly diseases of dairy cattle, understanding the TLR-mediated signaling pathways, particu- larly the LPS-mediated signaling, in bovine mammary epithelial cells is necessary.

In the host system, LPS capture is facilitated by LBP and the receptor complex comprised of CD14, MD-2 (or LY96), and TLR4, implying specificity of LPS recognition by this TLR. Several findings with knockout mice and human cell lines have established this fact (review by [39]). Our study however demonstrates that LPS up-regulates both TLR4 and TLR2 in bovine mammary epithelia cells. The up-regulation of TLR2 is supported by findings by Faure et al. [16] and Fan et al. [14] who demonstrated receptor cross talk in their studies. Both groups demonstrated that LPS is 
capable of activating TLR2 expression in an $\mathrm{NF}-\kappa \mathrm{B}$ dependent manner. They observed that the up-regulation of TLR2 was secondary to the activation of TLR4 signaling, rather than direct LPS activation of TLR2, due to the presence of NF- $\kappa B$ binding sites on TLR2. Upregulation of the transcription factor, NF- $\kappa \mathrm{B}$ was therefore crucial for LPS-TLR4 dependent up-regulation of TLR2 in these studies. As shown by our data, NF- $\kappa \mathrm{B}$ production tripled by the 6 th $\mathrm{h}$ post induction while TLR2 mRNA only reached significant levels (doubled) by the 24th hour, and continued to increase as NF- $\kappa \mathrm{B}$ increased. Therefore, it can be postulated that the increase of TLR2 depended on the increases of NF- $\kappa \mathrm{B}$. However, several studies have shown a lack of human or murine TLR2 involvement in LPS signaling $[15,20,41]$. Also, it is possible that the mammary epithelia cells or gland may have its own specific manner of responding to the presence of pathogenic products which may be different from other cell types and organs. In a recent study, Goldammer et al. [17] experimentally induced Staphylococcus aureus mastitis in bovine mammary gland and observed a coordinated up-regulation of the mRNAs of both TLR2 and TLR4. Staphylococcus aureus is a species of Gram-positive bacteria, which is expected to up-regulate only TLR2. In addition, TLR4 and TLR 2 expression has been observed in inflammation-induced renal epithelial cells [44] and in Trichonomas vaginalis (flagellated protozoan parasite) infected HeLa cells [9]. Taken together, these findings may point to yet unknown factors in the mammary gland that would facilitate recognition of microbial products (whether from Gram-negative or positive bacteria) by both TLR4 and TLR2. It may also be an evolutionarily acquired adaptive attribute of the mammary gland to help it fight infections since it is constantly under attack by invading pathogens. Furthermore, TLR2 has been shown to recognize LPS preparations from sources like Leptospira interrogans, Porphyromonas gingivalis, and Helicobacter pyroli, all non-enterobacteria [21, 36, 43]. Another study demonstrated TLR $2 / C D 14$ complex as the exogenous mediators of Trypanosoma cruzi induced inflammation [8].
Therefore, in addition to present established facts, CD14 may also play a role in TLR2 binding with pathogenic products and might have enabled the recognition of LPS from Gram-negative bacteria by this toll.

TLR4 specificity for LPS from Gramnegative bacteria has been demonstrated with TLR4 knock-out mice [23]. Furthermore, a mouse strain possessing a point mutation in the TLR4 gene was shown to be unresponsive to LPS [34]. Consequently, LPS as a potent immune activator can activate TLR4 at smaller concentrations than other activators (e.g. heat shock proteins, fibrinonectins, oligosaccharides, heparin sulfate, and fibrinogen) [39]. This is in good agreement with our study whereby an LPS concentration as low as $0.01 \mu \mathrm{g} / \mathrm{mL}$ was enough to significantly up-regulate TLR mRNA after $24 \mathrm{~h}$. Increasing the concentration of LPS did not result in any change in TLR4 mRNA abundance, except a slight but not significant increase at $10.0 \mu \mathrm{g} / \mathrm{mL}$ (as compared to $0.01 \mu \mathrm{g} / \mathrm{mL}$ ) indicating that a very low concentration of LPS or a very small number of attacking pathogens is enough to trigger optimal TLR4 signaling response. TLRs are comprised of a family of germline-encoded transmembrane receptors whose specificity in mode of action has been acquired, refined and perfected over time. Even an increase in the copy number of the TLR4 gene in an individual does not confer it too much advantage in its mode of action indicating a fine balance in gene dosage and action acquired over time. In a recent study, Roy et al. [35] investigated the response pattern of mice carrying one, two, or three copies of the TLR4 gene to Salmonella typhimurium infection and, although found a small difference in survival and bacterial load clearance in individuals carrying three copies of the gene, opined that two copies of the gene per individual represents the most optimal dose possible to fight infections.

The commencement of an infection is always preceded by an attack by a pathogen and in the case, for example, of mastitis induced by Escherichia coli usually occur through a 7day period. Host response to the initial phases of Escherichia coli mastitis is evident by the recruitment of neutrophils and eventually 
the production of pro-inflammatory cytokines. The progressive up-regulation of the mRNAs of TLR4 and TLR2 in response to LPS and the TLR4 signaling molecules in our study concurs well with the biological array of events that follow an infection of the mammary gland. Considering that the concentration of pathogenic ligands exposed to the host's cell surface increases as pathogens grow and multiply would give the host enough time to deal with it. The time-dependent up-regulation of the TLR4 signaling molecules therefore follows the biological sequel of events in response to increasing presence/concentration of bacterial ligands.

Following LPS binding to the receptor complex, CD14, MD-2 (or LY96), and TLR4, downstream activation of NF- $\kappa B$ is initiated through the MyD88 dependent pathway and IRF3 through the adaptors TICAM 1 and 2 also known as the MyD88 independent pathway [39]. Our finding has shown that MAC-T cells responded to the presence of LPS by upregulating MyD88 and NF- $\kappa \mathrm{B}$. Activation of $\mathrm{NF}-\kappa \mathrm{B}$ leads to induction and expression of inflammatory cytokines such as TNF $\alpha$, IL-6, IL-12, which are essential in inhibiting bacterial activity. MyD88 is a very important link between innate and acquired immunity since all TLRs, except TLR3, signal through it to production of inflammatory cytokines. This essential role was shown clearly in MyD88 deficient mice which failed to produce the representative inflammatory cytokines in response to TLR5 stimulator (flagellin) [19] and to stimulators for other TLRs [42]. Interestingly, our results indicate that the MyD88 independent path way in TLR4 signaling was activated in MAC-T cells as shown by the response patterns of TICAM2 and IRF3. IRF3 activation is responsible for the expression of IFN- $\beta$ and IFN inducible genes (e.g IP10, glucocorticoid-attenuated response gene 16). The up-regulation of these two transcription factors (NF- $\mathrm{KB}$ and IRF3) in the TLR4 signaling pathway in MAC-T cells supports the findings of several studies characterizing cytokine production by the mammary gland following bacterial infections $[4,30]$ and thus confirming the ability of the mammary gland to mount a robust innate immune response to these infections.

Over production of cytokines following infection however induces serious systemic disorders or septic shock and may lead to high mortality rates in the host [39]. Interestingly, the system has evolved its own mechanism of dealing with such situations. TOLLIP, an adaptor protein initially identified as an intermediate in IL-1 signaling has been recently shown to bind directly to TLR2 and TLR4 thus negatively regulating the activity of NF$\kappa B$ in TLR signaling [49] and limiting the over production of inflammatory cytokines. Our data showed an increased time dependent upregulation of $\mathrm{NF}-\kappa \mathrm{B}$ and TOLLIP after LPS induction. Our data therefore indicate that an increased up-regulation of TOLLIP is necessary to counter the effects associated with over expression of NF- $\kappa \mathrm{B}$, thus confirming the findings of Zhang and Ghosh [49].

To further suppress the multiplication of invading pathogens, the host system has been shown to initiate the processes of apoptosis through the binding of FADD (Fas-associated death domain protein) to the DD (death domain) of MyD88 and the recruitment of CASP8 $[3,13,27]$. The expression of NF- $\kappa B$ and IRF3 induced genes may cause changes in surrounding cells that enhance both innate and acquired responses to pathogenic ligands [27]. The expression pattern of CASP8 in our study shows a trend that did not necessarily concur with the expression patterns of both NF- $\kappa B$ and IRF3 but rather to the length of time cells were exposed to the presence of LPS. This shows a mechanism of response by cells to the presence of a pathogenic ligand and its attempt to deal with the intruder after the necessary genes have been up-regulated by NF$\kappa \mathrm{B}$ and IRF3. Impaired phagosome maturation in the absence of MyD88 or TLR4/TLR2 has been shown to impair phagocytosis of bacteria e.g. Escherichia coli, Staphylococcus aureus, and Salmonella typhimurium due to impaired phagosome maturation [6]. Therefore, the bovine mammary epithelial cells possess the capability of dealing with excess bacterial load by up-regulating the necessary mediators of apoptosis. 
In conclusion, our study demonstrates that the bovine mammary epithelial cells respond to the presences of LPS by activating the TLR4 signaling pathway which is necessary to initiate a robust defensive action against intruders. Signaling members of both the MyD88 dependent and independent pathways are actively up-regulated, thereby, ensuring that the necessary players are available to contribute to the regulated expression of inflammatory cytokines and controlled pathogen clearance. Thus, bovine mammary epithelial cells possess immune repertoires necessary to control invading pathogens.

Acknowledgements. This study was supported by funding from the Canadian Mastitis Research Network and a discovery grant from Natural Science and Engineering Research Council of Canada to X. Zhao.

\section{REFERENCES}

[1] Akira S., Uematsu S., Takeuchi O., Pathogen recognition and innate immunity, Cell (2006) 124:783-801.

[2] Alexopoulou L., Holt A.C., Medzhitov R., Flavell R.A., Recognition of double-stranded RNA and activation by toll-like receptor 3, Nature (2001) 413:732738.

[3] Bannerman D.D., Goldblum S.E., Mechanisms of bacterial lipopolysaccharide-induced endothelial apoptosis, Am. J. Physiol. Lung Cell. Mol. Physiol. (2003) 284:L899-L914.

[4] Bannerman D.D., Chockalingam A., Paape M.J., Hope J.C., The bovine innate immune response during experimentally-induced Pseudomonas aeruginosa mastitis, Vet. Immunol. Immunopathol. (2005) 107:201-205.

[5] Barber G.N., Host defense, viruses and apopotosis, Cell Death Differ. (2001) 8:113-126.

[6] Blander J.M., Medzhitov R., Regulation of phagosome maturation by signals from toll-like receptors, Science (2004) 304:1014-1018.

[7] Boudjellab N., Chan-Tang H.S., Li X., Zhao X., Interleukin 8 response by bovine mammary epithelial cells to lipopolysaccharide stimulation, Am. J. Vet. Res. (1998) 59:1563-1567.

[8] Campos M.A., Gazzinelli R.T., Trypanosoma cruzi and its components act as exogenous mediators of inflammation recognized through toll-like receptors, Mediators Inflamm. (2004) 13:139-143.

[9] Chang J.H., Park J.Y., Kim S.K., Dependence on p38 MAPK signaling in the up-regulation of TLR2, TLR4 and TLR9 gene expression in Trichomonas vaginalis treated HeLa cells, Immunology (2006) 118:164 170.

[10] Connor E.E., Cates E.A., Williams J.L., Bannerman D.D., Cloning and radiation hybrid mapping of bovine toll-like receptor-4 (TLR-4) signaling molecules, Vet. Immunol. Immunopathol. (2006) 112:302-308.

[11] Creagh E.M., Conroy H., Martin S.J., Caspaseactivation pathways in apopotosis and immunity, Immunol. Rev. (2003) 193:10-21.

[12] Cullor J.S., Shock attributable to bacterimia and endotoxemia in cattle: clinical and experimental findings, J. Am. Vet. Med. Assoc. (1992) 200:1894-1902.

[13] Dauphinee S.M., Karsan A., Lipopolysaccharide signaling in endothelial cells, Lab. Invest. (2006) 86:922.

[14] Fan J., Frey R.S., Malik A.B., TLR4 signaling induces TLR2 expression in endothelial cells via neutrophil NADPH oxidase, J. Clin. Invest. (2003) 112:1234-1243.

[15] Faure E., Equils O., Sieling P.A., Thomas L., Zhang F.X., Kirschning C.J., Polenturatti N., Muzio M., Arditi M., Bacterial lipopolysaccharide activates NF- $\mathrm{KB}$ through toll-like receptor 4 (TLR-4) in cultured human dermal endothelial cells: differential expression of TLR-4 and TLR-2 in endothelial cells, J. Biol. Chem. (2000) 275:11058-11063.

[16] Faure E., Thomas L., Xu H., Medvedev A.E., Equils O., Arditi M., Bacterial lipopolysaccharide and IFN- $\gamma$ induce toll-like receptor 2 and toll-like receptor 4 expression in human endothelial cells: role of NF- $\mathrm{\kappa B}$ activation, J. Immunol. (2001) 166:2018-2024 .

[17] Goldammer T., Zerbe H., Molenaar A., Schuberth H.J., Brunner R.M., Kata S.R., Seyfert H.M., Mastitis increases mammary mRNA abundance of $\beta$-defensin 5, toll-like receptor 2 (TLR2), and TLR4 but not TLR9 in cattle, Clin. Diagn. Lab. Immunol. (2004) 11:174185.

[18] Guillot L., Medjane S., Le-Barillec K., Balloy V., Danel C., Chignard M., Si-Tahar M., Response of human epithelial cells to lipopolysaccharide involves tolllike receptor 4 (TLR4)-dependent signalling pathways: evidence for an intracellular compartmentalization of TLR4, J. Biol. Chem. (2004) 279:2712-2718.

[19] Hayashi F., Smith K.D., Ozinsky A., Hawn T.R., Yi E.C., Goodlett D.R., Eng J.K., Akira S., Underhill D.M., Aderem A., The innate immune response to bacterial flagellin is mediated by toll-like receptor-5, Nature (2001) 410:1099-1103.

[20] Heine H., Kirschning C.J., Lien E., Monks B.G., Rothe M., Golenbock D.T., Cutting edge: cells that carry a null allele for toll-like receptor 2 are capable of responding to endotoxin, J. Immunol. (1999) 162:6971-6975.

[21] Hirschfeld M., Weis J.J., Toshchakov V., Salkowski C.A., Cody M.J., Ward D.C., Qureshi N., Michalek S.M., Vogel S.N., Signaling by toll-like receptor 2 and 4 agonists results in differential gene expression in murine macrophages, Infect. Immun. (2001) 69:1477-1482.

[22] Horng T., Barton G.M., Medzhitov R., TIRAP: an adapter molecule in the toll signaling pathway, Nat. Immunol. (2001) 2:835-841.

[23] Hoshino K., Takeuchi O., Kawai T., Sanjo H., Ogawa T., Takeda Y., Takeda K., Akira S., Cutting 
edge: toll-like receptor 4 (TLR4)-deficient mice are hyporesponsive to lipopolysaccharide: evidence for TLR4 as the Lps hene product, J. Immunol. (1999) 162:3749-3752.

[24] Hsu L.C., Park J.M., Zhang K., Luo J.L., Maeda S., Kaufman R.J., Eckmann L., Guiney D.G., Karin M., The protein kinase PKR is required for macrophage apoptosis after activation of toll-like receptor 4, Nature (2004) 428:341-345.

[25] Huynh H.T., Robitaille G., Turner J.D., Establishment of bovine mammary epithelial cells (MAC-T): an in vitro model for bovine lactation, Exp. Cell Res. (1991) 197:191-199.

[26] Kagan J.C., Medzhitov R., Phosphoinositidemediated adaptor recruitment controls toll-like receptor signaling, Cell (2006) 125: 943-955.

[27] Kaiser W.J., Offermann M.K., Apoptosis induced by the toll-like receptor adaptor TRIF is dependent on its interacting protein homotypic interaction motive, J. Immunol. (2005) 174:4942-4952.

[28] Kopp E., Medzhitov R., Recognition of microbial infection by toll-like receptors, Curr. Opin. Immunol. (2003) 15:396-401.

[29] Lee J.W., Paape M.J., Elsasser T.H., Zhao X., Elevated milk soluble CD14 in bovine mammary glands challenged with Escherichia coli lipopolysaccharide, J. Dairy Sci. (2003) 86:2382-2389.

[30] Lee J.W., Bannerman D.D., Paape M.J., Huang M.K., Zhao X., Characterization of cytokine expression in milk somatic cells during intramammary infections with Eschericha coli or Staphylococcus aureus by real-time PCR, Vet. Res. (2006) 37:219-229.

[31] McGuire K., Jones M., Werling D., Williams J.L., Glass E.J., Jann O., Radiation hybrid mapping of all 10 characterized bovine toll-like receptors, Anim. Genet. (2006) 37:47-50.

[32] Persson Waller K., Colditz I.G., Lun S., Ostensson K., Cytokines in mammary lymph and milk during endotoxin-induced bovine mastitis, Res. Vet. Sci. (2003) 74:31-36.

[33] Pfaffl M.W., Horgan G.W., Dempfle L., Relative expression software tool (REST) for group-wise comparison and statistical analysis of relative expression results in real-time PCR, Nucleic Acids Res. (2002) 30:e36.

[34] Poltorak A., He X., Smirnova I., Liu M.Y., Huffel C.V., Du X., Birdwell D., Alejos E., Silva M., Galanos C., Freudenberg M., Ricciardi-Castagnoli P., Layton B., Beutler B., Defective LPS signaling in $\mathrm{C} 3 \mathrm{H} / \mathrm{HeJ}$ and $\mathrm{C} 57 \mathrm{BL} / 10 \mathrm{ScCr}$ mice: mutation in Tlr4 gene, Science (1998) 282:2085-2088.

[35] Roy M.F., Larivière L., Wilkinson R., Tam M., Stevenson M.M., Malo D., Incremental expression of Tlr4 correlates with mouse resistance to Salmonella infection and fine regulation of relevant immune genes, Genes and Immunity (2006) 7:366-371.

[36] Smith M.F. Jr, Mitchell A., Li G., Ding S., Fitzmaurice A.M., Ryan K., Crowe S., Goldberg J.B., Toll-like receptor (TLR) 2 and TLR5, but not TLR4 are required for Helicobacter pylori-induced NF- $\mathrm{\kappa B}$ activation and chemokine expression by epithelial cells, J. Biol. Chem. (2003) 278:32552-32560.
[37] Sordillo L.M., Streicher K.L., Mammary gland immunity and mastitis susceptibility, J. Mammary Gland Biol. Neoplasia (2002) 7:135-146.

[38] Swanson K., Gorodetsky S., Good L., Davis S., Musgrave D., Stelwagen K., Farr V., Molenaar D., Expression of $\beta$-defensin mRNA, lingual antimicrobial peptide, in bovine mammary epithelial tissue is induced by mastitis, Infect. Immun. (2004) 72:73117314.

[39] Takeda K., Akira S., Toll-like receptors in innate immunity, Int. Immunol. (2005) 17:1-14.

[40] Takeuchi O., Akira S., MyD88 as a bottle neck in Toll/IL-1 signaling, Curr. Top. Microbiol. Immunol. (2002) 270:155-167.

[41] Takeuchi O., Hoshino K., Kawai T., Sanjo H., Takada H., Ogawa T., Takeda K., Akira S., Differential roles of TLR2 and TLR4 in recognition of Gramnegative and Gram-positive bacterial cell wall components, Immunity (1999) 11:443-451.

[42] Takeuchi O., Takeda K., Hoshino K., Adachi O., Ogawa T., Akira S., Cellular responses to bacterial cell wall components are mediated through MyD88dependent signaling cascades, Int. Immunol. (2000) 12:113-117.

[43] Werts C., Tapping R.I., Mathison J.C., Chuang T.H., Kravchenko V., Saint Girons I., Haake D.A., Godowski P.J., Hayashi F., Ozinsky A., Underhill D.M., Kirschning C.J., Wagner H., Aderem A., Tobias P.S., Ulevitch R.J., Leptospiral lipopolysaccharide activates cells through a TLR2-dependent mechanism, Nat. Immunol. (2001) 2:346-353.

[44] Wolfs T.G., Buurman W.A., van Schadewijk A., de Vries B., Daemen M.A., Hiemstra P.S., van ’t Veer C., In vivo expression of toll-like receptor 2 and 4 by renal epithelial cells: IFN-gamma and TNF-alpha mediated up-regulation during inflammation, J. Immunol. (2002) 168:1286-1293.

[45] Yamamoto M., Sato S., Hemmi H., Sanjo H., Uematsu S., Kaisho T., Hoshino K., Takeuchi O., Kobayashi M., Fujita T., Takeda K., Akira S., Essential role for TIRAP in activation of the signaling cascade shared by TLR2 and TLR4, Nature (2002) 420:324 329.

[46] Yamamoto M., Sato S., Hemmi H., Hoshino K., Kaisho T., Sanjo H., Takeuchi O., Sugiyama M., Okabe M., Takeda K., Akira S., Role of adaptor TRIF in the MyD88-independent toll-like receptor signaling pathway, Science (2003) 301:640-643.

[47] Yamamoto M., Sato S., Hemmi H., Uematsu S., Hoshino K., Kaisho T., Takeuchi O., Takeda K., Akira S., TRAM is specifically involved in the toll-like receptor 4-mediated MyD88-independent pathway, Nat. Immunol. (2003) 4:1144-1150.

[48] Yang Y., Zhou H., Yang Y., Li W., Zhou M., Zeng Z., Xiong W., Wu M., Huang H., Zhou Y., Peng C., Huang C., Li X., Li G., Lipopolysaccharide (LPS) regulates TLR4 signal transduction in nasopharynx epithelial cell line $5-8 \mathrm{~F}$ via $\mathrm{NF \kappa B}$ and MAPKs signaling pathways, Mol. Immunol. (2006) 44:984-992.

[49] Zhang G., Ghosh S., Negative regulation of tolllike receptor-mediated signaling by Tollip, J. Biol. Chem. (2002) 277:7059-7065. 